\title{
The use of radiosynovectomy in patients with juvenile idiopathic arthritis. Assessment of treatment efficacy and safety
}

\author{
Agnieszka Gazda ${ }^{1}$, Jarosław Ćwikła ${ }^{2}$, Beata Kołodziejczyk ${ }^{1}$, Izabela Szczygielska ${ }^{1}$, Elżbieta Hernik ${ }^{1}$, \\ Piotr Gietka ${ }^{1}$ D , Lidia Rutkowska-Sak ${ }^{1}$ ID \\ ${ }^{1}$ Clinic of Developmental Age Rheumatology, National Institute of Geriatrics, Rheumatology and Rehabilitation, Warsaw, Poland \\ ${ }^{2}$ Gammed Diagnostic and Treatment Center, Warsaw, Poland
}

\begin{abstract}
Objectives: The aim of the study was to evaluate the usefulness of knee joint radiosynovectomy (RS) in patients suffering from juvenile idiopathic arthritis (JIA).

Material and methods: One hundred RS procedures performed in 58 patients with JIA in average age 10.4 years were evaluated.

Results: After 6 weeks, a decrease in the number of cases with joint pain from $90.3 \%$ to $29 \%$, with joint oedema from $100 \%$ to $74.5 \%$, with joint exudate from $100 \%$ to $60.6 \%$, with gait disorders from $19.4 \%$ to $3.2 \%$, with joint mobility disorders from $51.1 \%$ to $26.6 \%$ in the RS cases was observed. A reduction of the score in the Colorado scale from 10.9 to 4.66 , in the pain visual analogue scale (VAS) from 50 to 10, in the illness VAS assessed by the patient/parent from 69.9 to 32.4, in the illness VAS assessed by the physician from 68.8 to 36.9 was observed. Six months after the RS procedure, a reduction in the number of cases with joint pain from $89.5 \%$ prior to the procedure to $29.5 \%$, with oedema from $100 \%$ to $58.3 \%$, with exudate from $100 \%$ to $46.9 \%$, with gait disorders from $20 \%$ to $2.1 \%$, with joint motility disorders from $51.1 \%$ to $26.1 \%$ was achieved. The score in the Colorado scale was reduced from 10.9 to 4.04 , in the pain VAS from 40 to 0 , in the illness VAS assessed by the patient/parent from 69.7 to 27.9 , in the illness VAS assessed by the physician from 68.8 to 32.4. In ultrasound examinations, the greatest improvement compared to the initial condition was recorded in the $6^{\text {th }}$ month after the RS. Radiosynovectomy was positively evaluated by parents and patients in 34 anonymous surveys. Early and late observations (average 1473 days) did not show lesions at the isotope injection site, and no neoplastic lesions were observed.

Conclusions: Radiosynovectomy is a valuable therapeutic option for local treatment in patients with JIA.

Key words: local treatment, juvenile idiopathic arthritis, radiosynovectomy, intraarticular injection.
\end{abstract}

\section{Introduction}

Radiosynovectomy (RS), as defined by the European Association of Nuclear Medicine, is a treatment method for inflammation and synovial hyperplasia in the joint using $\beta$ ionizing radiation emitted by radioisotopes (yttrium silicate/citrate ${ }^{90} \mathrm{Y}$ or rhenium sulfide ${ }^{186} \mathrm{Re}$ or erbium citrate ${ }^{169} \mathrm{Er}$ ), administered by intra-articular injection [1].

The procedure involves the application to the articular cavity, tendon sheath or bursa the radioisotope in colloid form with a particle size (from 2 to $10 \mu \mathrm{m}$ ) adjusted to the macrophages' ability to phagocytize it. Optimal ionizing radiation prevents the radioisotope from getting outside of the articular capsule, penetrating through the capillary fenestrations to the lumen of the blood and lymph vessels and further peripherally to other organs outside of the treated joint, or from permanently binding with other intra-articular elements, other than the treated synovial membrane. The radioisotope particles, after administration to the articular cavity,

Address for correspondence:

Agnieszka Gazda, Clinic of Developmental Age Rheumatology, National Institute of Geriatrics, Rheumatology and Rehabilitation,

1 Spartańska St., 02-637 Warsaw, Poland, e-mail: agnieszka.gazda@spartanska.pl

Submitted: 08.04.2021; Accepted: 04.08.2021 
penetrate into deeper layers of the synovial membrane where they are phagocytized by macrophages and other phagocytes associated with the ongoing inflammatory process. Irradiation of the synovial membrane by the radioisotope with a stream of electrons of $\beta$ radiation leads to changes in its structure, release of free radicals, damage and death of cells due to radiolysis (absorption of a high radiation dose), and stimulation of apoptosis of synovial cells. This results in inhibition of the ongoing inflammation and further in synovial fibrosis.

This method, considered a safe and non-invasive local treatment, is used in rheumatology, haematology and orthopaedics. The main indications for RS are chronic arthritis with synovial hypertrophy in rheumatoid arthritis (RA), juvenile idiopathic arthritis (JIA), peripheral arthritis in the course of spondyloarthropathies - particularly psoriatic arthritis (PSA) and undifferentiated arthritis. Radiosynovectomy is an effective treatment method for haemophilic arthropathy, reducing the frequency of articular bleeding and protecting the joint from progressive destruction [2]. Other indications for RS are as follows: arthritis caused by crystals deposition (gout, pseudogout) and pigmented villonodular synovitis [3] as well as RS may be a treatment method of recurrent joint exudates in patients after joint alloplasty (reaction to the foreign body). Radiosynovectomy is performed in patients with degenerative joint disease if there is an excessive inflammatory response in the joint, although degenerative joint disease alone is not an indication for RS [4].

During the developmental age, chronic inflammation of the synovial membrane occurs in the course of IIA. According to the current definition of the International League of Associations for Rheumatology (ILAR) classification of JIA, second revision Edmonton 2001, this is a heterogeneous group of arthritis of unknown aetiology, with symptoms onset before the age of 16 and with a continuous course for at least 6 weeks [5]. Depending on the number of affected joints, involvement of entheses, involvement of eyes, general symptoms and involvement of internal organs, 7 subtypes/ forms of this disease were distinguished, which also vary as to the pathogenesis:

- systemic-onset JIA,

- oligoarticular JIA,

- seronegative polyarticular JIA (pJIA RF-),

- seropositive polyarticular JIA,

- juvenile psoriatic arthritis (JPSA),

- enthesitis-related arthritis (ERA),

- undifferentiated JIA.

Modern JIA treatment - the use of disease-modifying antirheumatic drugs (DMARDs) and biological disease-modifying antirheumatic drugs (bDMARDs) improved the treatment efficacy, the patients' living comfort and reduced the complications of chronic arthritis. In the case of one or a few joints affected, local treatment is also used: intra-articular injections of glucocorticosteroids (GCS) and RS as well as arthroscopy and, rarely, operative synovectomy are also performed. In the past years before introduction of RS chemical synovectomy using e.g. Aethoxysklerol was used as a method of treatment.

The aim of the study was to carry out a clinical assessment of patients suffering from JIA in aspects of joint inflammation, assessment of disease activity scales, and ultrasound examination of joints after RS. Evaluation of the safety of RS, both in the early period and in the course of further available observation, was another aim of the present study.

\section{Material and methods}

The study was based on a retrospective analysis of medical documentation of patients with diagnosis of JIA who have been treated in the Developmental Age Rheumatology Clinic and Polyclinic of Rheumatology in the National Geriatrics, Rheumatology and Rehabilitation Institute (NGRRI) and documentation of these patients at the Gammed Diagnostic and Therapeutic Center and at the Nuclear Medicine Laboratory of the Central Clinical Hospital of the Ministry of the Interior and Administration in Warsaw.

The analysis of physical examination, data of observation of patients, interviews with parents and patients, and the parents' completion of the individual survey of parent/patient assessment of the RS procedure were performed. Approval of the Bioethics Committee at the NGRRI to conduct the study was received with the decision number KBT-7/7/2016 on 27.10.2016.

Criteria for inclusion in the study:

- patients with diagnosed JIA in which RS was performed due to current inflammation in the knee joint,

- RS performed during treatment with DMARD or bDMARD treatment for at least 3 months, at a stable dose of GCs if used,

- prior local treatment (intra-articular GC injections) at least 6 weeks before the RS,

- agreement of the parents and the patients (able to judge the situation) for this method of treatment.

Exclusion criteria were as follows:

- RS performed during a change in the primary treatment,

- lack of patients' parents' agreement for RS treatment. The assessment of pain [pain visual analogue scale (VAS; 1-100 mm)], oedema, exudate, joint mobility disorders and gait disorders, general illness assessment VAS $(1-100 \mathrm{~mm})$ in the opinion of the patient/parent and 
the physician, the paediatrically modified Colorado scale (with our own modifications available from the author) and assessment of improvement in ultrasound examination in the $6^{\text {th }}$ week and $6^{\text {th }}$ month after the knee joint RS was performed. Laboratory tests such as erythrocyte sedimentation rate (ESR), C-reactive protein (CRP), rheumatoid factor (RF), and HLA-B27 were included in analysis.

\section{Characteristic of the study group}

The study included 58 patients with JIA who underwent 100 knee joint RS procedures between 2007 and 2018. The average age at which the procedures were performed was 10.4 years including the youngest group of patients $n=4$ (6.9\%) up to 5 years of age, in which the RS was performed at the age of 3 and $1 / 12,3$ and 9/12, 3 and 6/12, 4 and 8/12; duration of the disease, in years, up to the RS procedures was 4.7 ( \pm 3.0$)$. Girls represented $75.4 \%(n=43)$ of the study group.

The diagnosis of JIA was established in accordance with the ILAR criteria. The highest number of RS was performed in patients with the diagnosis of persistent oligoarticular JIA-61\%, 15\% were performed in patients with extended oligoarticular JIA, 13\% in patients with pJIA RF-, 3\% in patients with JPSA, $6 \%$ in patients with ERA, and $2 \%$ in patients with undifferentiated arthritis.

In the studied group, HLA-B27 was found in $29.3 \%$ of the patients, and in the RS analysis HLA-B27 was present in $32.7 \%$ of the cases.

Seventy percent of the study group had normal ESR and CRP results, the ESR median was $10 \mathrm{~mm} / \mathrm{h}$, the CRP median was $5 \mathrm{mg} / \mathrm{l}$.

In X-ray: prior to the RS, according to the Steinbrocker classification, class I was found in $96.8 \%$ of patients, class II in 3.4\% (joint space narrowing), and 30.3\% of patients had epiphyseal hypertrophy in the affected joint.

General treatment in the period during which the RS was performed included: $93 \%(n=93)$ were treated with methotrexate (MTX), in 62\% ( $n=62)$ of this group monotherapy was used, $38 \%$ of patients were treated with 2 conventional DMARDs and $11 \%(n=11)$ with combined treatment MTX and etanercept. As a second cDMARD to MTX, hydroxychloroquine, chloroquine, sulfasalazine, cyclosporine A, or azathioprine was used. In 37\% $(n=37)$ of analysed patients, in addition to DMARDs, GC (prednisone) was used in a dose of $0.3 \mathrm{mg} / \mathrm{kg}$ bw/day (36\%; $n=36)$ or higher, $0.5 \mathrm{mg} / \mathrm{kg}$ bw/day $(1 \% ; n=1)$.

All of the patients included in the analysis previously received local treatment:

- knee joint punctures with intra-articular GC injection (methylprednisolone acetate) on average 3.6 times \pm 1.5 ,

- chemical synovectomy using Aethoxysklerol in 17 joints $(n=16)$,
- arthroscopic joint synovectomy in 3 patients (5\% of the analysed knee joint RS procedures).

Each patient was qualified for the RS by the attending rheumatologist. The parents signed an informed consent form for administering the radioisotope to the treated child. The procedures were carried out in accordance with the guidelines for radiological protection approved by the National Atomic Energy Agency.

In most of the patients the RS was performed using rhenium sulfide in colloid form, labelled ${ }^{186} \mathrm{Re}$; only 3 procedures were performed using yttrium 90 silicate in colloid form, labelled ${ }^{90} \mathrm{Y}$. The average isotope dose used was $155.2 \pm 21.8 \mathrm{MBq}$, depending on the type of the joint and the age of the patient, given in approximately 1-3.5 $\mathrm{ml}$ of radioisotopic solutions. Sixty-eight RS procedures were performed as the first RS in the given patient. In 32 cases RS procedures were performed as the $2^{\text {nd }}$ or $3^{\text {rd }}$ procedure in the same joint.

An anonymous follow-up survey concerning early symptoms after the RS and the parents' and patients' evaluation of the procedure has been developed.

\section{Results}

A significant improvement ( $p \leq 0.001)$ was obtained for all symptoms assessed in physical examination, compared to the initial condition prior to the RS at 6 weeks after the RS procedure which was expressed in:

- reduction in the percentage of cases of joint pain from $90.3 \%$ to $29 \%$,

- reduction in the percentage of cases of joint oedema from $100 \%$ to $74.5 \%$,

- reduction in the percentage of cases of joint exudate from $100 \%$ to $62.6 \%$,

- reduction in the percentage of cases of gait disorders from $19.4 \%$ to $3.2 \%$,

- reduction in the percentage of patients with restrictions of joint mobility from $51.1 \%$ to $26.6 \%$.

A significant reduction $(p \leq 0.001)$ in clinical symptoms of knee joint inflammation was observed in the $6^{\text {th }}$ week, compared to the state prior to the RS, assessed in scales. These results are shown in Table I.

All patients had ultrasound (US) assessment before RS, at week 6 US was available to 18 patients and the comparative assessment revealed:

- joint exudate still present in $88.9 \%$ of the cases (prior to the RS 100\%; $p=0.486$ ), but a statistically significant reduction of the volume and area of exudate $(p=0.023)$ was observed,

- in the assessment of synovial membrane lesions with regard to thickening (corresponding to mild hypertrophy of the synovial membrane visible in 1 joint compartment and moderate hypertrophy) or synovial hypertrophy (a high degree of hypertrophy of the syno- 
Table I. Clinical evaluation in scales 6 weeks after the radiosynovectomy (RS), comparison with the pre-procedure state (note: the result before and after 6 weeks had to be known)

\begin{tabular}{|lccc|}
\hline Parameters & Prior to the RS & 6 weeks after the RS & $p$-value \\
\hline Colorado scale $(n=94)$ & $10.9 \pm 2.7$ & $4.66 \pm 3.18$ & $<0.0001$ \\
\hline Pain VAS assessment $(n=93)$ & $50(0-90)$ & $10(0-80)$ & $<0.0001$ \\
\hline Illness VAS patient/parent $(n=93)$ & $69.9 \pm 13.3$ & $32.4 \pm 16.7$ & $<0.0001$ \\
\hline IIIness VAS physician $(n=94)$ & $68.8 \pm 12.4$ & $36.9 \pm 16$ & $<0.0001$ \\
\hline
\end{tabular}

vial membrane visible in the whole joint) there was no statistically significant difference, $100 \%$ vs. $94.4 \%$,

- a significant reduction in the number of examinations with synovial hyperaemia was observed, 77.8\% vs. $37.9 \%(p=0.020)$, and reduced hyperaemia intensity in cases where it was present ( $p=0.0011$ ). Severe hyperaemia prior to the RS was found in $22.2 \%$ of the examinations, after 6 weeks $5.6 \%$, moderate $33.3 \%$ vs. $16.7 \%$, mild $22.2 \%$ vs. $16.7 \%$. Obtained results are presented in Table II.
Six months after the RS procedure assessment revealed in the physical examination a significant reduction of knee joint inflammation symptoms, in comparison to the initial condition ( $p \leq 0.001-0.002$ ):

- reduction in the percentage of cases with joint pain from $89.5 \%$ prior to the procedure to $29.5 \%$,

- reduction in cases of joint oedema from $100 \%$ to $58.3 \%$

- reduction in cases of joint exudate from 100\% to $46.9 \%$,

Table II. Ultrasound. Assessment before radiosynovectomy (RS) and 6 weeks after the procedure $(n=18)$

\begin{tabular}{|c|c|c|c|}
\hline Parameters & $\begin{array}{c}\text { Prior to the RS } \\
n(\%)\end{array}$ & $\begin{array}{c}\text { After } 6 \text { weeks } \\
n(\%)\end{array}$ & $p$-value \\
\hline \multicolumn{4}{|l|}{ Exudate } \\
\hline Lack & 0 & $2(11.1)$ & \multirow[t]{4}{*}{$0.023(\mathrm{~F})$} \\
\hline $1-5 \mathrm{~mm}$ & $1(5.6)$ & $7(38.9)$ & \\
\hline 6-10 mm & 7 (38.9) & $4(22.2)$ & \\
\hline$>10 \mathrm{~mm}$ & $10(55.6)$ & $5(27.8)$ & \\
\hline \multicolumn{4}{|l|}{ Exudate } \\
\hline Absent & 0 & $2(11.1)$ & \multirow[t]{2}{*}{$0.486(F)$} \\
\hline Present & $18(100.0)$ & $16(88.9)$ & \\
\hline \multicolumn{4}{|l|}{ Synovial membrane } \\
\hline Without lesions & 0 & $1(5.6)$ & \multirow[t]{3}{*}{$0.355(F)$} \\
\hline Thickened & $11(61.2)$ & $14(77.8)$ & \\
\hline Hypertrophic & $7(38.9)$ & $3(16.7)$ & \\
\hline \multicolumn{4}{|l|}{ Synovial membrane } \\
\hline Without lesions & 0 & $1(5.6)$ & \multirow[t]{2}{*}{$1.000(\mathrm{~F})$} \\
\hline With lesions & $18(100.0)$ & $17(94.4)$ & \\
\hline \multicolumn{4}{|l|}{ Hyperaemia } \\
\hline 0 & $4(22.2)$ & $11(61.1)$ & \multirow[t]{4}{*}{$0.001(F)$} \\
\hline 1 mild & $4(22.2)$ & $3(16.7)$ & \\
\hline 2 moderate & $6(33.3)$ & $3(16.7)$ & \\
\hline 3 severe & $4(22.2)$ & $1(5.6)$ & \\
\hline \multicolumn{4}{|l|}{ Hyperaemia } \\
\hline Absent & $4(22.2)$ & $11(61.1)$ & \multirow[t]{2}{*}{$0.020(\mathrm{tS})$} \\
\hline Present & $14(77.8)$ & 7 (38.9) & \\
\hline
\end{tabular}

$F$-non-parametric Friedman test, $t S$ - Student t-test 
- improvement with regard to gait mechanics; the percentage of cases with gait disorders was reduced from $20 \%$ to $2.1 \%$,

- the percentage of cases of cumulative joint mobility disorders was reduced from $51.1 \%$ RS prior to the procedure to $26.1 \%$ after.

In mobility assessment after 6 weeks and 6 months, minor improvement was noted in patients with an isolated flexion contracture ( $9.6 \%$ vs. $8.5 \%$ of cases), and a significant reduction in the number of cases with limited range of flexion in the knee joint and cases with both limited range of flexion and flexion contracture was observed.

A significant reduction $(p \leq 0.001)$ in clinical symptoms of knee joint inflammation was observed in the $6^{\text {th }}$ month of observations assessed in scales; the results are presented in Table III.

The patients achieved a significant improvement in the assessment of clinical symptoms during the first 6 weeks after the RS. In the period of 6 weeks to 6 months, only improvement in the intensity of oedema was significant ( $p=0.019$ ) and the improvement with regard to the presence of exudate reached the value $p=0.057$. Also improvements were documented in the assessment in the scales: Colorado, pain VAS, illness VAS assessed by the patient/parent, and illness VAS assessed by the physician. The greatest improvement was obtained in the patient assessment in the first 6 weeks after the RS ( $p \leq 0.001$ ). In the following months, further improvement was achieved in these parameters, but only improvement in the illness VAS assessed by the physician after 6 months versus 6 weeks was statistically significant ( $p=0.046)$, while the Colorado scale result was close to statistical significance $(p=0.056)$.

Fifty-two US results before the RS and 6 months after this procedure were compared. In the $6^{\text {th }}$ month after the RS joint exudate was present in $82.7 \%$ of the examined joints, but a significant reduction in the exudate size was found ( $p<0.0001)$. After 6 months, the image of the synovial membrane was normal in $30.8 \%$ of the cases; a thickened membrane was described in 55.8\% of the ultrasounds (prior to the RS 78.9\%), no hypertrophic synovial membrane was found in the examinations (prior to the RS $21 \%$ ), and a fibrotic one in $14 \%$. The percentage of examinations in which synovial hyperaemia was found after 6 months was $23.1 \%$ vs. $63.4 \%$ before RS.

Obtained results are shown in Table IV.

There were no significant differences in the response to the RS in the clinical assessment and scales in patients in whom HLA-B27 was found in comparison to the group in which HLA-B27 was not present.

When comparing responses to the RS performed on patients older than 10 years to groups of patients in
Table III. Clinical assessment in scales. Comparison after 6 months in regard to the radiosynovectomy (RS) (note: the result before and after 6 weeks had to be known)

\begin{tabular}{|lccc|}
\hline Parameters & $\begin{array}{c}\text { Prior } \\
\text { to the RS }\end{array}$ & $\begin{array}{c}6 \text { months } \\
\text { after the RS }\end{array}$ & -value \\
\hline $\begin{array}{l}\text { Colorado scale } \\
(n=96)\end{array}$ & $10.9 \pm 2.7$ & $4.04 \pm 3.80$ & $<0.0001$ \\
\hline Pain VAS $(n=95)$ & $40(0-90)$ & $0(0-70)$ & $<0.0001$ \\
\hline $\begin{array}{l}\text { IIIness VAS patient/ } \\
\text { parent }(n=96)\end{array}$ & $69.7 \pm 13.3$ & $27.9 \pm 23.8$ & $<0.0001$ \\
\hline $\begin{array}{l}\text { IIIness VAS physician } \\
(n=96)\end{array}$ & $68.8 \pm 12.3$ & $32.4 \pm 21.3$ & $<0.0001$ \\
\hline
\end{tabular}

whom the RS was performed at the age of 10 and less, after 6 weeks only the response assessed in the Colorado scale was significantly better in the younger group. In the evaluation 6 months and 6 weeks after RS in the assessed scales in both age groups the response to the RS was similar.

There was no significant difference in the response to the RS between patient groups with illness onset up to the $5^{\text {th }}$ year of life and after the $5^{\text {th }}$ year of life, or between groups of patients suffering from arthritis for more than three years compared to groups of patients suffering from arthritis for a shorter period.

During 6 months' observation, in the clinical assessment by the physician, $85.6 \%$ of the RS patients achieved clinical remission (on drugs) or significant improvement in the treated joints. In $14.5 \%$ of cases there was no improvement, or the improvement was unsatisfactory.

According to late observations after 6 months, exacerbation of arthritis in $71.1 \%$ of cases occurred when the primary treatment was discontinued by the patient or physician or when the drugs were taken irregularly. In $28.85 \%$ of the cases exacerbation occurred also in joints other than the joint in which the RS was performed.

In none of the patients were local complications observed after the RS procedure. Also, no cancer was diagnosed in any patient during the observation period.

A late analysis of joint US examinations after RS (in total 86 examinations), over an average period of 1380 days $( \pm 620)$, revealed: in $24.4 \%$ a normal image, in $59.3 \%$ typical signs of inflammation of varying intensity, in $16.2 \%$ other lesions (such as: heterogeneously increased echostructure of the femoral condyles' hyaline cartilage with or without its segmental thinning, patellar lateralization during contraction of the quadriceps femoris, a heterogeneous image - secondary degenerative lesions in the anterior horn of the medial meniscus, moderate degenerative lesions in the knee joint's articular edges). 
Table IV. Ultrasound examination $(n=52)$ comparison of the image before the radiosynovectomy (RS) and after 6 months

\begin{tabular}{|c|c|c|c|}
\hline Parameters & $\begin{array}{c}\text { Prior to the RS } \\
n(\%)\end{array}$ & $\begin{array}{c}\text { After } 6 \text { months } \\
n(\%)\end{array}$ & $p$-value \\
\hline \multicolumn{4}{|l|}{ Exudate $(n=52)$} \\
\hline Lack & 0 & $9(17.3)$ & \multirow[t]{4}{*}{$<0.0001(\mathrm{~F})$} \\
\hline $1-5 \mathrm{~mm}$ & $2(3.9)$ & $28(53.9)$ & \\
\hline $6-10 \mathrm{~mm}$ & $23(44.2)$ & $14(26.9)$ & \\
\hline$>10 \mathrm{~mm}$ & $27(51.9)$ & $1(1.9)$ & \\
\hline \multicolumn{4}{|l|}{ Exudate $(n=52)$} \\
\hline Absent & 0 & $9(17.3)$ & \multirow[t]{2}{*}{$0.0001(F)$} \\
\hline Present & $52(100)$ & $43(82.7)$ & \\
\hline \multicolumn{4}{|c|}{ Synovial membrane $(n=52)$} \\
\hline Without lesions & 0 & $16(30.8)$ & \multirow[t]{4}{*}{$<0.00001(F)$} \\
\hline Thickened & $41(78.9)$ & $29(55.7)$ & \\
\hline Hypertrophic & $11(21.1)$ & $0(0.0)$ & \\
\hline Fibrotic & 0 & $7(13.5)$ & \\
\hline \multicolumn{4}{|c|}{ Synovial membrane $(n=52)$} \\
\hline Without lesions & 0 & $16(30.8)$ & \multirow[t]{2}{*}{$<0.00001(\mathrm{Ch})$} \\
\hline With lesions & $52(100)$ & $36(69.2)$ & \\
\hline \multicolumn{4}{|c|}{ Hyperaemia $(n=52)$} \\
\hline 0 & $18(34.6)$ & $40(76.9)$ & \multirow[t]{4}{*}{$<0.0008(\mathrm{~F})$} \\
\hline 1 mild & $10(19.2)$ & $5(9.6)$ & \\
\hline 2 moderate & $19(36.6)$ & $6(11.6)$ & \\
\hline 3 severe & $5(9.6)$ & $1(1.9)$ & \\
\hline \multicolumn{4}{|c|}{ Hyperaemia $(n=52)$} \\
\hline Absent & $18(34.6)$ & $40(76.9)$ & \multirow[t]{2}{*}{$<0.0001(\mathrm{tS})$} \\
\hline Present & $34(65.4)$ & $12(23.1)$ & \\
\hline
\end{tabular}

$F-$ non-parametric Friedman test, $C h-\chi^{2}$ difference test, $t S-S t u d e n t$-test

In radiological examinations of knee joints (X-ray of 60 knee joints) performed during an average of 1082 days \pm 650 from the RS, $38.3 \%$ of the examination results were normal; apart from that, typical inflammatory changes were found, most often epiphyseal hypertrophy of the joint affected by the inflammation process in $31.8 \%$, joint space narrowing in $18.4 \%$, periarticular osteoporosis in 10\%; no erosions were described in any examination. Other lesions accounted for 36.7\%. According to the Steinbrocker classification, class I was found in $81.6 \%$ of the cases, class II in $18.4 \%$ (prior to the RS I- $96.8 \%$, II - 3.4\%).

Other lesions found in X-ray examination were mostly minor pathological lesions such as: a fibrous cortical defect, a dense bone island, an unfused ossification centre, anatomical variations (a fault at the edge of the lateral tibial condyles), a cup-shaped depression with sclerotic borders of the femoral condyle, a segmental invagination of the tibial condyle, an archwise convex outline of the anterior part of the patella, and in a single case it was a degenerative lesion.

Magnetic resonance (MR) images of knee joints available in 8 cases of knee joints previously subjected to an RS procedure were inspected; on average in the period of 3 years and 5/12 after the RS, typical lesions in the course of a very active, treatment-resistant joint inflammatory process were found. The MR examinations did not show any neoplastic or pathological lesions which could correspond to damage after undergoing the RS.

An anonymous survey completed by parents/patients assessed the early follow-up after the RS procedure (34 surveys). Pain after the procedure, assessed by a VAS (1-100 mm) scale, was comparable to the pre-procedure joint pain, $4.9 \pm 2.8$ vs. $4.8 \pm 2.8$. The necessity to administer analgesics after the procedure, which were used for 1-3 days, was reported by $18.8 \%$ of the parents. Joint 
oedema larger than before the RS procedure occurred in $52.9 \%$ of the cases; it lasted on average 5 days. A temporary joint contracture after the RS occurred in $17.7 \%$ of the cases; it lasted 2-7 days, on average 5. A noticeable improvement in the joint occurred between 2 and 4 weeks after the RS. According to $85.3 \%$ of the parents, the RS brought a long-term improvement in the affected joint; $82.3 \%$ of the children responded the same. The results of this assessment are presented in Table V.

\section{Discussion}

Radiosynovectomy has been widely used as a local treatment method in adults with rheumatic diseases with arthritis for many years. The first publication of Fehlinger [6] on treatment with gold isotopes in patients with knee joint inflammation in the course of RA dates back to 1952. In Poland, RS procedures have been performed since 1969, as Fiedorowicz-Fabrycy [7] concluded in a publication from 1984, presenting the results of knee joint treatment with the phosphorus radioisotope ${ }^{32} \mathrm{P}$ in 112 patients with RA, ankylosing spondylitis (AS), PSA, JIA.

Radiosynovectomy is a recognized method of treatment for haemophilic arthropathy, including in the developmental age. Researchers pioneering this method in the developmental age, such as Lofqwist, Mathew, Kavakli, de la Corte Rodriguez and others, and in Poland Łaguna, reported the beneficial effect of RS in haemophilia patients without observing any complications of such treatment [8-13].

However, there are only a few publications on the application of this method to arthritis in developmental age. Using the experience of applying RS in children with haemophilia since 2005 we started to refer patients with JIA to RS procedures in our clinic. In 2011, we published the first observations on the use of RS in patients with JIA [14]. The current analysis included 100 knee joint RS procedures performed in 58 patients with JIA. It should be emphasized that with RS, simultaneously, DMARD drug treatment was always used, in $11 \%$ of the procedures also bDMARDs. In the $6^{\text {th }}$ week after the RS, a significant reduction in clinical symptoms of knee joint inflammation was demonstrated. The greatest improvement was observed regarding the reduction of cases with joint pain (61.3\%) but we observed still a high percentage of patients with joint oedema (74.5\%, reduction by $25.5 \%)$ and exudate $(60.6 \%$, reduction by $39.4 \%)$ after 6 weeks, which was the effect of treating every case of oedema and exudate that was found in physical examination.

Presentation of the inflammation in scales allowed for the gradation of symptoms; a statistically significant reduction in clinical symptoms of knee joint inflammation in the $6^{\text {th }}$ week after the RS was observed, assessed via the Colorado scale (score reduction from $10.9 \pm 2.7$ to $4.66 \pm 3.18$ ), reduction of the pain VAS from 50 to 10 , the illness VAS assessed by the patient/parent from $69.9 \pm 13.3$ to $32.4 \pm 16.7$ and illness VAS assessed by the physician from $68.8 \pm 12.4$ to $36.9 \pm 16$.

In Zalewska's study [15], in a group of patients with RA, significant pain reduction was achieved as an early (4 weeks) benefit of RS - this is confirmed in all of the parameters assessed in the pain category of the WOMAC index. Matryba's study [16] showed pain and oedema reduction in patients with RA assessed in the average period of 56 days from knee joint RS in $68.7 \%$ of the patients. Liepe's [17] study showed a significant

Table V. Results of the survey filled out by parents and patients, 34 surveys

\begin{tabular}{|c|c|}
\hline \multicolumn{2}{|l|}{ Parameters } \\
\hline Assessment of pain in the affected joint in the VAS scale of 1 to 10 prior to the RS procedure, mean \pm SD & $4.9 \pm 2.8$ \\
\hline $\begin{array}{l}\text { Assessment of pain in the affected joint in the scale of } 1 \text { to } 10 \text { for the first } 3 \text { days after the RS } \\
\text { procedure, mean } \pm S D\end{array}$ & $4.8 \pm 2.8$ \\
\hline Joint oedema greater than before the procedure, $n[\%]$ & $18(52.9)$ \\
\hline Time for oedema to persist, if it occurred, in days, mean (range) & $5(3-7)$ \\
\hline Occurrence of contracture after the procedure, $n[\%]$ & $6(17.7)$ \\
\hline Duration of joint contracture, if it occurred, in days, mean (range) & $5(2-7)$ \\
\hline $\begin{array}{l}\text { According to the parent's assessment, whether the procedure was painful - answer yes } \\
\text { ( } 2 \text { answers missing), } n[\%]\end{array}$ & $19(59.4)$ \\
\hline $\begin{array}{l}\text { Whether it was necessary to administer analgesics - answer yes } \\
\text { How long analgesics were administered, in days, } n[\%]\end{array}$ & $6(18.8)$ \\
\hline After what time there was a noticeable improvement, in weeks, mean (range) & $3(2-4)$ \\
\hline Long-term improvement according to the parent's assessment - answer yes, $n[\%]$ & $29(85.3)$ \\
\hline Long-term improvement according to child's assessment - answer yes, $n$ [\%] & $28(82.3)$ \\
\hline
\end{tabular}


pain reduction also as an early effect of RS, and according to an assessment in the $6^{\text {th }}$ month, a reduction from 6 to 3 in the 10-point pain VAS scale. Also 6 months after the RS procedure, our patients experienced a significant improvement in the assessment of inflammatory symptoms such as pain, oedema and exudate and the reduction of gait and mobility disorders.

The results of our patients with JIA were compared to the results of observations of adult patients who underwent RS due to inflammatory joint diseases such as RA, PsA, and spondyloarthropathy (SpA), although the course of the disease is different in children than in adult patients; despite active joint inflammation some of the young patients do not report pain - in our group $11 \%$ of the cases - and in some of them the pain is not as severe as that reported in adult patients. Among our patients, the pain VAS prior to the RS was identified on average as 40-50 mm (VAS scale). The comparison of these two groups of patients with arthritis is difficult because of frequently co-existing degenerative lesions in the adult group. In addition, researchers use different methods to assess improvement; in several publications the improvement was presented in a 4-level subjective scale of the patient's assessment: excellent improvement (very good), good, moderate and "no improvement" [18].

In Liepe's [19] study, after 577 RS procedures, an excellent and good response after 3 months from the RS using ${ }^{90} Y$ was obtained in $57 \%$ of the knee joints, while no response was reported in $24 \%$. Zwolak et al. [20] reported that in patients with RA a very good or good response was achieved after the knee joint RS using ${ }^{90} \mathrm{Y}$ in $58.1 \%$ of the joints. According to Jahanier et al. [21], one year from the RS patients with RA achieved a significant improvement in the pain VAS, functional mobility, joint tenderness and joint oedema in $76 \%$ of cases. In the experience of Miszczyk et al. [22] after 6 months of observation, $47.6 \%$ of patients experienced partial pain relief (the scale: 0 - no pain, 1 - partial pain reduction, 2 - pain comparable to before the RS), while in 33\% total pain relief was achieved.

In our patients during 6 months of observation up to $85.6 \%$ of patients achieved remission of inflammatory symptoms or significant-satisfactory improvement in the treated joint according to clinical assessment of the physician. These results are slightly better than those presented in the meta-analysis published in 2002 by Kresnik [23]. The authors presented results of the use of RS in the treatment in a total of 2190 joints of patients with RA in which the response in different radiological classes I-II in the Steinbrocker classification was respectively $72.8 \% \pm 12.3 \%, 64 \% \pm 17.3 \%$.
Although the radiological examinations in the present patients revealed an early class of lesions according to the Steinbrocker classification (I or II), the inflammatory process in the joint was long lasting or recurred persistently, which was demonstrated by epiphyseal hypertrophy in the affected joint in $30.3 \%$ of the examinations - this is a typical radiological image for the developmental age. This confirms that comparison between patients with JIA and defined RA may be difficult and may lead to incomplete conclusions.

Compared to the US prior to the RS $(n=18)$ and 6 weeks after the RS; joint exudate was still present (but in low intensity), there were no differences in the assessment of synovial thickening/hypertrophy, but there was significant reduction of synovial hyperaemia, which confirmed the influence of RS on inflammatory activity.

In Zalewska's [15] study, in the RA and SpA groups, a significant reduction in synovial hypertrophy was noted at one month after the RS procedure in RA patients, a reduction in the thickness of the synovial membrane from $7.6 \pm 2.57 \mathrm{~mm}$ to $4.71 \pm 1.85 \mathrm{~mm}$ was observed, and a statistically significant reduction in the joint exudate observed, from $8.91 \pm 3.65 \mathrm{~mm}$ to $5.53 \pm 2.95 \mathrm{~mm}$. In another study US was performed on average 56 days after the RS; joint exudate was found in $76.8 \%$ and synovial hypertrophy in $87.5 \%$ [16].

These observations placed our results in between, with joint exudate present in $82.7 \%$ of the examined joints, but we observed a significant reduction in the exudate size $(p<0.0001)$ and improvement regarding the synovial membrane $(p<0.00001)$. What is important in the present study, there was no synovial hypertrophy after RS (prior to the RS 21\%) and in 30.8\% of cases the US image was normal (prior to the RS 0\%). So, the greatest improvement in physical examination and in scales was found in the early period after the RS, but the greatest improvement compared to the initial condition in ultrasound examinations was noted after 6 months. The observations also confirmed increased sensitivity of the US examination over physical examination in detecting inflammatory lesions in joints in patients with JIA.

In many cases of JIA despite the absence of symptoms in clinical assessment by the patient and the physician, moderate or mildly active inflammation was still confirmed in the US.

In the literature, opinions on the efficacy of RS depending on the diagnosis are divergent. In FiedorowiczFabrycy's [7] studies, the best response to RS was shown by the patients with PSA, AS and with the RA group with class II of X-ray lesions according to the Steinbrocker classification. In Zalewska's study [15], the best RS outcome was achieved in patients with RA. Zwolak's work [20] indicated a very good or good response to RS in 
both the RA and the SpA group. In our work taking into consideration that patients with presence of HLA-B27 may in the future develop full symptoms of ankylosing spondylitis (AS) or PsA, the response to RS in patients with the presence of HLA-B27 and without the HLA-B27 was compared but no significant difference in the response to RS was found between those groups.

Studies in adult patients with RA highlighted a better response to $\mathrm{RS}$ in an earlier stage of the disease and at a younger age [22, 23]. Comparison in our study response to RS in older ( $>10$ years old) and younger ( $<10$ years old) children revealed only difference in the Colorado scale 6 weeks after the RS as better in the younger age group. There were no significant differences in the response to RS between patients affected by IIA for a longer period before the RS (> 3 years) and less than 3 years, as well as between the group of patients with the development of JIA at the younger age ( $\leq 5$ years of age) and after 5 years of age.

Like other researchers after the RS we observed an increase of inflammatory symptoms such as joint pain and oedema and the necessity to administer analgesics after the procedure for 1-3 days; pain was reported by $18.8 \%$ of parents and $52.9 \%$ reported oedema larger than before the RS that lasted on average for 5 days. After the procedure $17.7 \%$ of children experienced a temporary joint contracture that on average lasted for 5 days. In Liepe's observations [17] only 16\% of the patients experienced oedema and temporary joint pain intensification. In Tebib's study [24] early side effects were reported in up to $24 \%$ of the patients (oedema, pain). In the procedure applied to our patients, they received a radiocolloid without GCs The described symptoms were temporary and they were not severe.

There was no infection as a complication after RS in our patients. Although the occurrence of joint infection after the RS was also described, the frequency of infection was estimated as 1 per 35,000 procedures [25]. In a previous cited study [19] from 2015 as 1 per 15,000 joints treated with RS and according to the Rodriguez-Merchan observations [26] septic arthritis occurred in 1 out of 500 performed RS procedures. Felis-Giemza et al. [27] described 6-month observations of 47 patients suffering from rheumatic diseases (RA, AS, PSA, JIA) with concomitant treatment of RS (76 procedures) basically treated with bDMARDs (mainly TNF- $\alpha$ inhibitors, also tocilizumab, in a single case rituximab) and no infections adverse event was described.

In local complications after RS skin necrosis, hardto-heal ulcerations and post-radiation dermatitis were described [28-30]. It is worth underlining that in the applied procedure, after administration of the radioisotope, the $2 \mathrm{ml}$ needle was flushed with a 1-2\% ligno- caine solution; none of our patients experienced local complications

Long-term observations indicate the safety of this treatment method in adults. Increasing observations in the developmental age, especially in haemophilic patients, indicate safety in this age group as well.

In 2002, Dunn [31] described 2 cases of acute lymphoblastic leukaemia in patients at the ages of 9 and 14 years; the disease occurred one year after the RS performed using the radiocolloid ${ }^{32} \mathrm{P}$, which is not currently used in Europe. No direct link to the RS was found, but careful assessment of risk factors and possible benefits of RS procedures was recommended. There are no reports in the literature about the development of haematological complications following RS procedures using rhenium. In our long-term observations, on average $1473 \pm 702$ days from the RS, median 1395, longest observation time 3423 days, shortest observation time 326 days, no cancer was diagnosed in any patient.

In 2015, Rodriguez-Merchan and Valentino [32] summarized the use of RS and the safety of this method in young haemophilia patients, on the basis of a literature review from the MEDLINE database (PubMed), Google Scholar, and Cochrane Library. It was found that the radiation dose after RS procedures in children with haemophilic arthropathy is minimal, it does not reach hazardous concentrations, and the data suggest that there is no increased risk of cancer.

In 2009, the results of a meta-analysis of literature on radiosynovectomy using yttrium and erbium were published, based on an analysis of 4379 joints treated with RS (including 3540 joints using yttrium). The opinion was formulated that the best candidates for RS are patients with chronic synovial membrane inflammation after 1 intra-articular GC injection or with recurrence of inflammation within 3 months after 1 intra-articular GC injection administered in one or a few joints, in which the disease is well controlled in other joints [33]. It was indicated that the duration of the inflammation should not be long and that the radiological changes should be of low severity.

\section{Conclusions}

Based on the present results RS brought a significant improvement after 6 weeks and 6 months compared to the pre-RS state in all of the evaluated clinical parameters (pain, oedema, joint exudate, joint mobility disorders, gait disorders) and confirmation of improvement in scales: Colorado, pain VAS, illness VAS assessed by the patient/parent, illness VAS assessed by the physician. The greatest clinical improvement in patients after RS was observed in the first 6 weeks after the proce- 
dure but the greatest improvement in US examination compared to the initial condition was recorded in the $6^{\text {th }}$ month after RS. According to the parent's assessment, a significant improvement was observed as early as 3 weeks after the procedure. Satisfactory improvement/ remission in the joint lasted on average for 560 days.

Radiosynovectomy is an effective and safe therapeutic method for the local treatment of chronic knee joint inflammation in patients with $\|$ A.

This method is a good option for patients with JIA as a complementary treatment to the basic treatment with DMARDs. This method is applicable to the treatment of persistent inflammatory conditions in individual joints, with low activity of the inflammatory process in laboratory tests.

The decision concerning this treatment should be made in a team of an experienced rheumatologist, nuclear medicine specialist and orthopaedist, and such treatment should be conducted in strict accordance with the safety rules for patients and staff.

The authors declare no conflict of interest.

\section{References}

1. Clunie G, Fisher M, EANM. EANM Procedure guidelines for radiosynovectomy. Eur J Nucl Med Mol Imaging 2003; 30: BP12-16, DOI: 10.1007/s00259-002-1058-0.

2. Rampersad AG, Shapiro AD, Rodriguez-Merchan EC. Radiosynovectomy: review of literature and report from two haemophilia treatment center. Blood Coagul Fibrinolysis 2013; 24: 455-470, DOI: 10.1097/MBC.0b013e3283602a28.

3. Nassar WA, Bassiony AA, Elghazaly HA. Treatment of diffuse pigmented villonodular synovitis of the knee with combined surgical and radiosynovectomy. HSS J 2009; 5: 19-23, DOI: 10.1007/s11420-008-9104-5.

4. Schneider P, Farahati J, Reiners C. Radiosynovectomy in rheumatology, orthopedics, and hemophilia. J Nucl Med 2005; 46 Suppl 1: 48S-54S.

5. Petty RE, Southwood TR, Manners P, et al. International League of Association for Rheumatology Classification of Juvenile Idiopathic Arthritis: second revision. Edmonton, 2001. J Rheumatol 2004; 31: 390-392.

6. Fehlinger K, Schmid J. Local therapy of rheumatic diseases. Wien Z Inn Med 1952; 33: 351-363.

7. Fiedorowicz-Fabrycy I. Wyniki leczenia przewlekłych wysiękowych zapaleń stawów kolanowych za pomocą synowiortezy izotopowej P-32 w świetle badań własnych. Ann Acad Med Stetin 1984; 30: 321-357.

8. Löfqwist T, Petersson C. Synoviorthesis in young patients with hemophilia and inhibitory antibodies. Pediatr Hematol Oncol 1992; 9: 167-170, DOI: 10.3109/08880019209018332.

9. Mathew P, Talbut DC, Frogameni A, et al. Isotopic synovectomy with P-32 in paediatric patients with haemophilia. Haemophilia 2000; 6: 547-555, DOI: 10.1046/j.1365-2516.2000.00406.x.
10. Kavakli K, Aydogdu S, Taner M, et al. Radioisotope synovectomy with rhenium 186 in haemophilic synovitis for elbows, ankle and schoulders. Haemophilia 2008; 14: 518-523, DOI: 10.1111/j.1365-2516.2008.01691.x.

11. De la Corte-Rodriguez H, Rodriguez-Merchan EC, JimenezYuste V. Radiosynovectomy in hemophilia: quantification of its effectiveness through the assessment of 10 articular parameters. J Thromb Haemost 2011; 9: 928-935, DOI: 10.1111/j.15387836.2011.04246.x.

12. Alioglu B, Ozsoy H, Koca G, et al. The effectiveness of radioisotope synowectomy for chronic synovitis in Turkish paediatric haemophiliacs: Ankara experience. Haemophilia 2010; 16: 932-936, DOI: 10.1111/j.1365-2516.2010.02276.x.

13. Łaguna P, Żbikowski P, Ćwikła JB, et al. Radiosynowektomia u dzieci z artropatią hemofilową z wykorzystaniem ${ }^{186}$ Re. Nowa Pediatr 2010; 4: 115-120.

14. Gazda A, Królicki L, Gietka P, et al. Synowektomia radioizotopowa u dzieci chorych na młodzieńcze idiopatyczne zapalenie stawów - obserwacje własne. Reumatologia 2011; 49: 156-161.

15. Zalewska J, Węgierska M, Barczyńska T, et al. Efficacy of radiation synovectomy (radiosynovectomy or radiosynoviorthesis) with yttrium-90 in exudative inflammation of synovial membrane of knee joints in patients with rheumatic diseases - preliminary report. Reumatologia 2016; 54: 3-9, DOI: 10.5114/ reum.2016.58754.

16. Matryba M, Ćwikła JB, Wisłowska M, et al. Ocena skuteczności zabiegu radiosynowektomii $u$ chorych z przewlekłymi wysiękowymi zapaleniami stawów. Probl Lek 2011; 46: 12-14.

17. Liepe K, Zaknun JJ, Padhy A, et al. Radiosynovectomy using yttrium-90, phosporus-32 or rhenium-188 radiocolloids versus corticoid instillation for rheumatoid arthritis of the knee. Ann Nucl Med 2011; 25: 317-323, DOI: 10.1007/s12149-011-0467-1.

18. Liepe K. Efficacy of radiosynovectomy in rheumatoid arthritis. Rheumatol Int 2012; 32: 3219-3224, DOI: 10.1007/s00296011-2143-0.

19. Liepe K. Radiosynovectomy in the therapeutic management of arthritis. World I Nucl Med 2015; 14: 10-15, DOI: 10.4103/ 1450-1147.150509.

20. Zwolak R, Majdan M. Methods of efficacy assessment of the knee joint radiosynoviorthesis- personal experience. Wiad Lek 2018; 71: 10-16.

21. Jahangier ZN, Moolenburgh JD, Jacobs JW, et al. The effect of radiation synovectomy in patients with persistent arthritis: a prospective study. Clin Exp Rheumatol 2001; 19: 417-424.

22. Miszczyk M, Jochymek B, Miszczyk L, et al. The results of 394 consecutive cases of knee joint radiation synovectomy (radiosynoviorthesis) using 90Y. Ann Nucl Med 2020; 34: 94-101, DOI: 10.1007/s12149-019-01418-w.

23. Kresnik E, Mikosh P, Gallowitsch HJ, et al. Clinical outcome of radiosynoviorthesis; a meta-analysis including 2190 treated joint. Nucl Med Commun 2002; 23: 683-638, DOI: 10.1097/ 00006231-200207000-00013.

24. Tebib JG, Manil LM, Mödder G, et al. Better results with rhenium-186 radiosynoviorthesis than with cortivazol in rheumatoid arthritis (RA): a two-year follow-up randomized controlled multicentre study. Clin Exp Rheumatol 2004; 22: 609-616. 
25. Das B. Role of radiosynovectomy in the treatment of rheumatoid arthritis and hemophilic arthropathies. Biomed Imaging Interv J 2007; 3: e45, DOI: 10.2349/biij.3.4.e45.

26. Rodriguez-Merchan EC, De la Corte-Rodriguez H, JimenezYuste V. Radiosynovectomy in haemophilia: long-term results of 500 procedures performed in a 38-year period. Thromb Res 2014; 134: 985-990, DOI: 10.1016/j.thromres.2014.08.023.

27. Felis-Giemza A, Chojnowski M, Rejmer J, et al. Safety and efficacy of radionuclide synovectomy in patients with persistent inflammatory of single joint in the course of biological therapy. Ann Rheum Dis 2019; 78: 707-708.

28. Oztürk H, Oztemür Z, Bulut O. Treatment of skin necrosis after radiation synovectomy with yttrium-90: case report. Rheumatol Int 2008; 28: 1067-1068, DOI: 10.1007/s00296-008-0571-2.

29. Garcia-Colmenero L, Marton-Ezquerra G, Monfort J, Pujol RM. Persistent cutaneous ulcers after Yttrium-90 synovectomy, an unusual complication: two case reports and review of the literature. Int Wound J 2017; 14: 508-511, DOI: 10.1111/iwj. 12636.

30. Chojnowski MM, Płazińska MT, Chojnowski MS, et al. Beta burns following radionuclide synovectomy. Reumatologia 2018; 56: 184-189, DOI: 10.5114/reum.2018.76905.

31. Dunn AL, Bush MT, Wyly JB, Abshire TC. Radionuclide synovectomy for hemophilic arhropathy: a comprehensive review of safety and efficacy and recommendation for a standardized treatment protocol. Thromb Haemost 2002; 87: 383-393.

32. Rodriguez-Merchan EC, Valentino LA. Safety of radiation exposure after radiosynovectomy in paediatric patients with haemophilia. Haemophilia 2015; 21: 411-418, DOI: 10.1111/hae. 12668.

33. van der Zant FM, Boer RO, Moolenburgh JD, et al. Radiation synovectomy with (90)Yttrium, (186)Rhenium and (169)Erbium: a systematic literature review with meta-analyses. Clin Exp Rheumatol 2009; 27: 130-139. 